\title{
Endoscopic removal of a proximally migrated biliary stent using a novel gooseneck snare: the "EndoCowboy"
}

Proximal migration often occurs as an adverse event of biliary stent placement, with a reported migration rate of $3.1 \%$ $4.9 \%$ [1]. Although various techniques have been reported for endoscopic removal of proximally migrated biliary stents, the procedure is still technically demanding and time-consuming, and occasionally unsuccessful [2-4]. We describe a useful technique for endoscopic removal of a proximally migrated biliary stent using a novel gooseneck snare (॰Fig. 1).

A man in his $70 \mathrm{~s}$ who had undergone placement of a 7-Fr straight plastic stent for benign biliary stricture was admitted to retrieve or exchange the stent; however, we noticed during endoscopic retrograde cholangiopancreatography

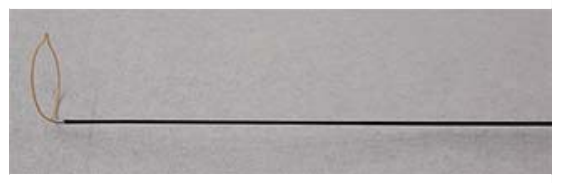

- Fig. 1 The novel snare has a microsnare loop that forms a $90^{\circ}$ angle like a gooseneck (EndoCowboy; Piolax Medical Devices, Kanagawa, Japan).
(ERCP) that the stent had migrated proximally into the common bile duct ( Fig.2a). To remove the stent, biliary wire-guided cannulation was first performed, with the cannula (MTW Endoskopie, Wesel, Germany) being inserted near the distal end of the stent. After the guidewire had been removed, a gooseneck snare (EndoCowboy; loop width $9 \mathrm{~mm}$; Piolax Medical Devices, Kanagawa, Japan) was inserted through the lumen of the prepositioned cannula ( $\triangleright$ Fig.2b). Once the snare loop had been passed over the stent, the snare

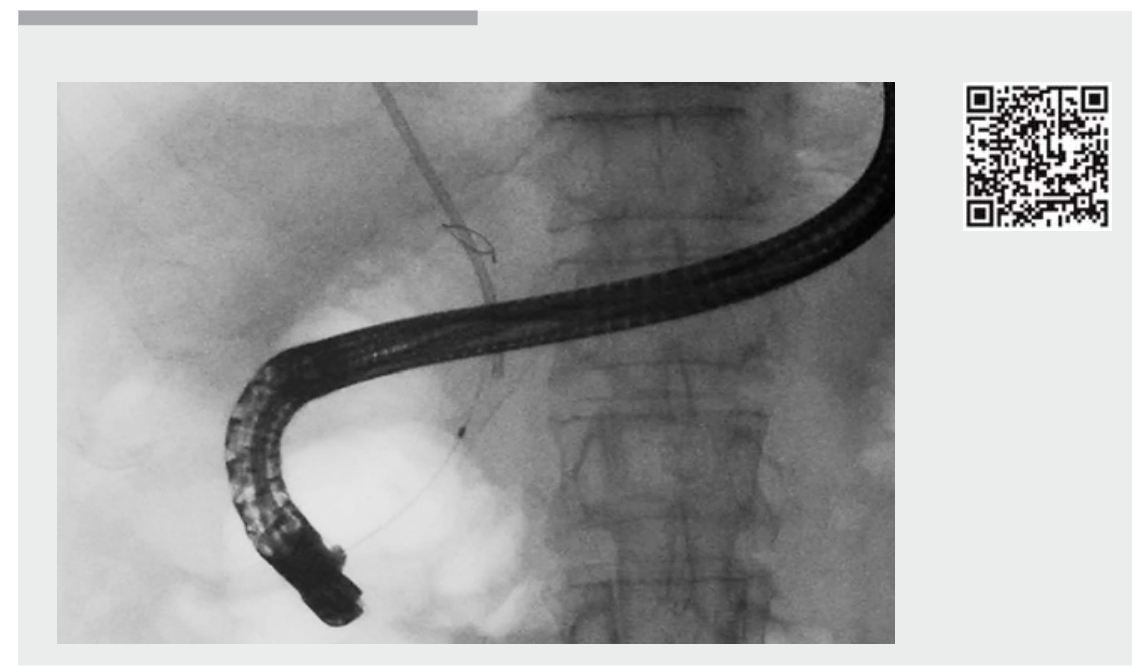

$\checkmark$ Video 1 A gooseneck snare is inserted through the lumen of the prepositioned cannula and the loop is passed over the stent, before the snare is pulled tight, grasping the stent. Finally, the cannula and snare are simultaneously pulled down and the stent is successfully removed.
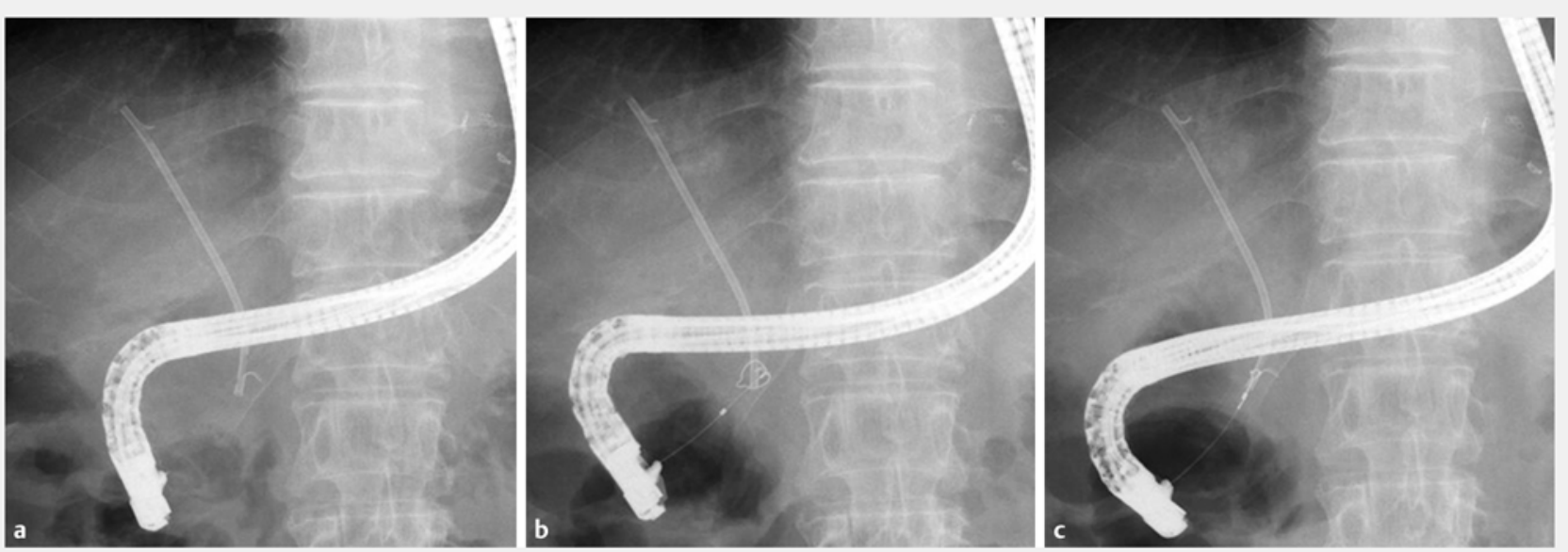

- Fig. 2 Radiographic images during endoscopic retrograde cholangiopancreatography showing: a the previously placed 7-Fr plastic stent that had migrated proximally into the common bile duct; $\mathbf{b}$ a gooseneck snare that was inserted through the lumen of a prepositioned cannula; $\mathbf{c}$ the stent, which had been grasped by the snare loop, being pulled down and removed. 
was pulled tight, grasping the stent ( Fig. 2c). Finally, the cannula and snare were simultaneously pulled down and the stent was successfully removed though the scope with no adverse events ( Video 1).

A gooseneck snare has a microsnare loop forming a $90^{\circ}$ angle just after exiting the outer sheath. It is useful for retrieving and manipulating foreign objects in the cardiovascular system [5], but until now there have been no devices for endoscopic use. The EndoCowboy was developed for ERCP. Its 2700-mm length is suitable for an endoscopic device, and various loop sizes are available to suit the diameter of the bile duct. This novel gooseneck snare can therefore be a useful option for the removal of proximally migrated stents and is recommended to have on standby.

Endoscopy_UCTN_Code_TTT_1AR_2AZ

\section{Competing interests}

None
The Authors

Tadahisa Inoue, Rena Kitano, Yuji Kobayashi, Norimitsu Ishii, Kiyoaki Ito, Masashi Yoneda Department of Gastroenterology, Aichi Medical University School of Medicine, Aichi, Japan

\section{Corresponding author}

\section{Tadahisa Inoue}

Department of Gastroenterology, Aichi Medical University School of Medicine, 1-1 Yazakokarimata, Nagakute, Aichi 480-1195, Japan

Fax: +81-561-633208

tinoue-tag@umin.ac.jp

\section{References}

[1] Kawaguchi Y, Ogawa M, Kawashima Y et al. Risk factors for proximal migration of biliary tube stents. World J Gastroenterol 2014; 20 : $1318-1321$

[2] Lee JH, Yan SL, Chen CH et al. Endoscopic retrieval of a proximally migrated biliary plastic stent using a guidewire loop technique. Endoscopy 2014; 46: E232 -E233

[3] Liatsos C, Kyriakos N, Anthopoulos G et al. An alternative method of endoscopic retrieval of a proximally migrated biliary plastic stent using a "sphincterotome hooking the stent” technique. Endoscopy 2015; 47: E64-E65
[4] Granata A, Curcio G, Ligresti D et al. Singlestep retrieval of a proximally migrated biliary stent. Endoscopy 2015; 47: E284 -E285

[5] Koseoglu K, Parildar M, Oran I et al. Retrieval of intravascular foreign bodies with goose neck snare. Eur J Radiol 2004; 49: 281 - 285

\section{Bibliography}

DOI https://doi.org/10.1055/s-0043-119982

Published online: 9.10.2017

Endoscopy 2017; 49: E321-E322

(c) Georg Thieme Verlag KG

Stuttgart · New York

ISSN 0013-726X

\section{ENDOSCOPY E-VIDEOS \\ https://eref.thieme.de/e-videos}

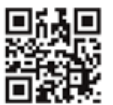

Endoscopy E-Videos is a free access online section, reporting on interesting cases and new techniques in gastroenterological endoscopy. All papers include a high quality video and all contributions are freely accessible online.

This section has its own submission website at https://mc.manuscriptcentral.com/e-videos 